\title{
Effect of Early Ambulation on Reducing Respiratory Tract Infection among Postoperative Elderly Patients with Abdominal Surgeries
}

\section{Aml Sabra Abu Bakr,1 Hoda Diab Fahmy Ibrahim 2, Tohamy Abdallah Tohamy 3, Inshrah Roshdy Mohammed 4, Jehan Abd} El-Rahem Mohamed5.

Assistant Lecturer in Medical Surgical Nursing (Gerontological Nursing), Faculty of Nursing-Minia University.

Prof .dr. of Community Health Nursing. Faculty of Nursing- Assiut university

Prof. dr. of General Surgery \&Endoscopies, Faculty of Medicin- Minia university

Assistant prof. \&Head of Medical-Surgical Nursing, Faculty of Nursing - Minia University.

Lecturer of Medical-Surgical Nursing (Gerontological Nursing), Faculty of Nursing - Minia University.

*Email of the corresponding author: amlsabra@mu.edu.eg

\section{Abstract}

Background: Abdominal surgery is one of the most frequent surgical procedures performed in age 65 and more. postoperative respiratory tract infection (RTIs) is the most common serious complication after this type of surgery with reported incidence between $17-88 \%$. Delayed mobilization was associated with a three-fold increase in RTIs. Aim of the study: To evaluate the effect of early ambulation on reducing RTIs among postoperative elderly patients with abdominal surgeries. Research design: Quasi-experimental research design was utilized in the current study. Subjects: Convenient sample including 80 elderly patients male and female, classified equally into two equal groups; study group $(n=40)$ and control group $(n=40)$, were collected through one year. Setting: This study was carried out at the general surgery departments (A and C) at Minia University Hospital. Tools of data collection: three tools were utilized in collecting data. Tool I: patient interview structured questionnaire, Tool II: patient's physical and respiratory assessment; Tool III: early ambulation record. Results: current study findings revealed that the $87.5 \%$ of the study group were free from postoperative RTIs. In contrast to, $85 \%$ of the control group had postoperative RTIs. Conclusion: The current study findings concluded that, early ambulation had a synergetic positive effect on reducing postoperative RTIs, improving respiratory parameters and decreased length of hospital stay among elderly with laparotomy. Recommendations: Hospitals should recommend implementing protocols for postoperative early ambulation as a routine hospital policy among all general surgical patients in all age groups.

Key Words: Elderly, abdominal surgery, respiratory tract infections, early ambulation, postoperative.

\section{Introduction}

Surgical procedures are now more common in the elderly because of longer life expectancies and enhanced surgical safety. Fifty percent of individuals older than 65 years undergo surgical procedures during their remaining years. Abdominal surgery is one of the most common operative procedures performed among the elderly surgical patients including both emergency and elective surgical interventions which constituted $36 \%$ (Chen et al., 2011).

Age-related physiological changes which include decrease in cognition, cardiac, respiratory, renal functions and other co-morbidities, as well, dependence on activities of daily living and frailty are interrelated and overlapping. These interplaying factors work to demand multifaceted care in an elderly surgical patient. (Tan \&Chua, 2013)

The primary concerns of the postoperative nursing care and monitoring for the hospitalized elderly patients in the general surgical units at the initial hours postoperative involves; adequate ventilation, hemodynamic stability, incisional pain control, preventing nausea and vomiting, assessing the neurological status, prevention from fall, surgical site integrity, dressing, ensuring tubes and lines are well secured, and amount of drainage, and spontaneous voiding, as well as, assessing capillary refill time, percentage of oxygen administration, oxygen saturation using pulse oximetery, intake and output charts, bowel sounds, performing respiratory exercises etc.,.... (Griffiths, 2014)

P a g e $\mid \mathbf{1 1 0}$
Postoperative respiratory tract infection (RTIs) are more common in elderly surgical patients with abdominal surgery due to lack of lung inflation that occurs due to change of breathing pattern, prolonged recumbent positioning, also, adds to impairment of mucociliary clearance with decrease cough effectiveness and increase risk associated with retained pulmonary secretions. In addition to, anaesthesia, opioids, analgesics and postoperative pain, they also contributes to change in ventilation pattern. (Masse, 2017)

To decrease the incidence of these complications, several studies highlighted that, practicing postoperative early ambulation in elderly patients with abdominal surgery promotes clearance of thick secretions and production of surfactant, improving lung expansion and decreases hypoventilation. As well as responsible for $71 \%$ reduction of postoperative RTIs Chatterley, L. (2017). It also gives positive results on both physical and psychological status and help elderly to return to their activities of daily living within a shorter period of time (Sabate, 2014).

\section{Significance of the study:}

Abdominal surgeries are among the most common operations performed in older patients. Postoperative RTIs are more prevalent in elderly patients with this type of surgery, with incidence varying from $6 \%$ to $80 \%$ (Bustamante, et al., 2017). Early ambulation play an 
important role in mobilizing bronchial secretion, improving oxygenation and reducing postoperative RTIs.

\section{Aim of the Study}

The aim of the present study was to evaluate the effect of early ambulation on reducing the respiratory tract infection among postoperative elderly patients with abdominal surgeries.

\section{Research hypothesis}

Using early ambulation for the studied group would reduce the respiratory tract infection among postoperative elderly patients with abdominal surgeries than control group.

\section{Subjects and Methods}

\section{Research design}

Quasi-experimental research design was utilized in the current study.

\section{Setting:}

The current study was carried out at the general surgery departments (A and C) at Minia University Hospital.

\section{Sample and sampling:}

Convenient sample of 80 elderly patients male and female were collected through one year, and they were classified equally into two groups; study group $(n=40)$ who performed early ambulation and control group $(n=40)$.

\section{Inclusion criteria:}

- Patients had 60 years old and more .

- Patients with elective abdominal surgeries performed by conventional laparotomy.

- Both gender.

\section{Exclusion criteria:}

- Patient's with neuropsychiatry diseases.

- Patient with preoperative respiratory tract infections, COPD and asthma.

- Patient with emergency abdominal surgeries.

- Patients with uncontrolled postoperative complications.

- Patients with uncontrolled chronic disease.

- Immobilized patient.

\section{Setting:}

The current study was carried out at the general surgery departments (A and C) at Minia University Hospital.

Tools of data collection: - three tools were used:

Tool I: Patient interview structured questionnaire. It covered two main parts:
- Part I; The bio-socio-demographic data of the patients which included (age, gender, level of education, and...........etc.

- Part II; The medical and surgical patient's assessment data included: Past and present medical data such as; history of smoking, recurrent chest infections, and date of admission, diabetes, hypertension, and ect,.... The current surgical data such as; surgical diagnosis, absence or presence of NGT, postoperative analgesia, ect,....

Tool II: Patient's physical and respiratory assessment that included :

- Measuring vital signs as temperature, pulse, respiration.

- Respiratory assessment such as chest sounds, oxygen saturation, RTIs manifestations as cough, sneezing, runny nose, sore throat, and etc....

\section{Tool III: Early ambulation record:}

- Used to record frequency of early ambulation step such performance as ankle planter flexion, getting out in bed, sitting, standing, waking in room and corridor.

\section{Tools validity:-}

Content validity was done to identify the degree to which the used tools measure what was supposed to be measured. The developed tools were examined by a panel of three experts opinion in the field of the study \{Minia University - faculty of nursing (Medical Surgical Nursing Department) $\}$ All jury members (100\%) agreed that current study tools were valid and relevant with the aim of the study.

\section{Tools reliability:}

Intraclass correlation coefficients at baseline and follow up was performed for reliability testing internal consistency for the modified Medical Research Council dyspnea scale were $0.84-0.90$.

\section{Pilot study:}

A pilot study was carried out on $10 \%(n=8)$ of the total sample to test the clarity of tools and estimate the time required for fulfilling it. Based on results of the pilot study no modifications or refinements were done and the subjects included to the actual sample.

\section{Ethical Considerations:}

An official permission to conduct the study was obtained from the Ethical committee in the Faculty of Nursing, Dean of nursing faculty and the Manager of Minia University Hospital, the Head of the General Surgery Departments ( A and C) and agreement from Egypt academic for research center and technology. to carry out 
this study. Subject's participation in this study was voluntary and each involved subject was informed about the purpose, procedure, benefits, and nature of the study, and that he/she had the right to withdraw from the study at any time without any rationale, then oral consents were obtained. Confidentiality and anonymity of each subject were ensured through coding of all data and protecting the obtained data. Subjects were informed that obtained data will not be included at any further researches without a second oral consent.

Educational training practices about the postoperative early ambulation formulated by the researchers after revising extensive relevant literature review such as (Tariq, 2017) \& (Castelino, 2016,), and other information from websites. They were applied to reduce the postoperative RTIs among elderly patients with abdominal surgeries. They included Arabic photo brochure.

The researchers asked the participants to ambulate as soon as possible for at least 2 hours on day of surgery, and after that, ambulated for six hours per day till the 5 th postoperative day. Some assistance were provided to them to maintain safety. Duration of ambulation according to the elderly patient's tolerance. Early ambulation involved ankle planter flexion, getting out in bed, standing, walking in room, walking in corridor, stair climbing, and side lying position. Early ambulation record was designed to record frequency of early ambulation steps performed by the participants in the study group from the 1 st to the 5 th postoperative day.

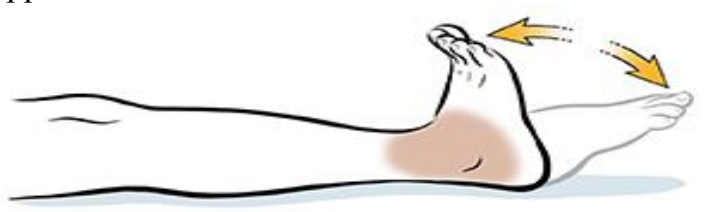

Ankle planter flexion: Bend and stretch the ankles up and down firmly and quickly (repeat 10 times) Figure (1).

Figure (1) Churchill surgical physiotherapy team, (2018).

Getting out in bed: (figure: $2,3,4$ )

Step 1: Roll onto your side, with your knees bent.

Step 2: Move your feet off the bed. Push your body up to a sitting position.

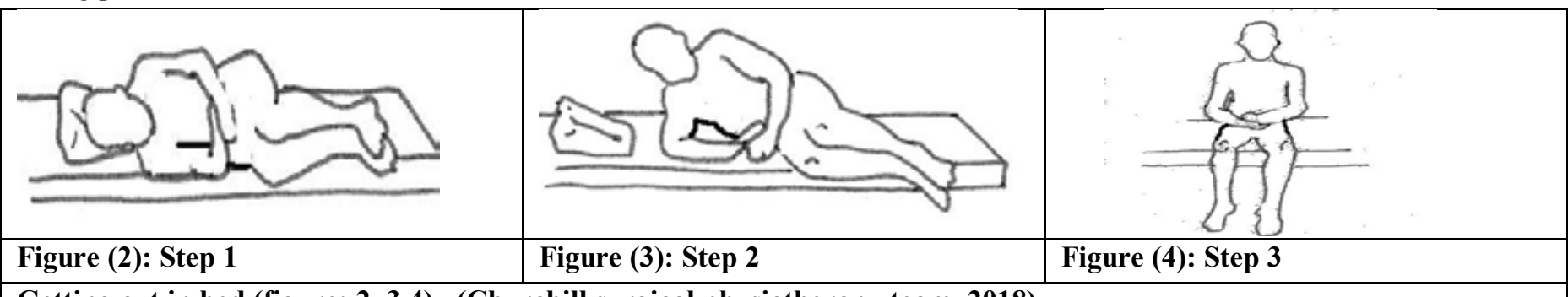

Getting out in bed (figure: $2,3,4$ ), (Churchill surgical physiotherapy team, 2018)

\section{Sitting:}

Sit upright in a supportive chair, if possible, with both feet on the floor. Do not slouch. You may find it helpful to place a small cushion or rolled towel in the small of your back. (10 minutes recommended). ( Churchill surgical physiotherapy team, 2018)

\section{Standing or walking:}

- Starting to walk after surgery must be slowly to avoid feeling dizzy or faint when first getting up after surgery:

- Dangle at the bedside for a few minutes

- Move from the bed to a chair

- Walk in the hallways for 20 minutes or according to patient tolerance. (Churchill surgical physiotherapy team, 2018)

\section{Procedure:}

- The current study was conducted by preparing of different data collection tools, in addition to,
Step 3: Sit on the side of the bed before you stand up. (Churchill surgical physiotherapy team, 2018) 
follow the prescribed instructions. The number of total sessions during training them average from 23 sessions varied according to each participant understanding, and every session lasted 30-45 minutes. The demonstration and re-demonstration was done by the study group to ensure that the participant can perform this procedure perfectly.

- Each participant was informed by the researchers to perform and repeat early ambulation daily from the 1 st to 5th day postoperative. After that, the researchers performed respiratory assessment daily after the participant practiced early ambulation by using the second and third tools (physical and respiratory assessment sheet and early ambulation record)

- On the other hand; the researchers trained the internship nursing students as co-researchers who had shift in the same study setting to follow up the study group who was applied early ambulation in accurate time during specific work shift to ensure that the elderly patients perform the procedures when the researchers not found, as elderly surgical patients were considered critically ill and easy forget, so, they need close observation to perform the procedures.

\section{Statistical analysis of data:}

Data were summarized, tabulated, and presented using descriptive statistics in the form of means and standard deviations as a measure of dispersion. A statistical package for the social science (SPSS), version (20) was used for statistical analysis of the data, as it contains the test of significance given in standard statistical books. Qualitative data were expressed as percentage. Correlation coefficient was done by using Pearson correlation test. Fisher's Exact test is a way to test the association between two categorical variables. when in case of small cell sizes (expected values less than 5). Chi-square test is used when the cell sizes are expected to be large.

\section{Results}

Table (1): Distribution of the study and control groups regarding their Socio demographic characteristics $(n=80)$

\begin{tabular}{|c|c|c|c|c|c|c|}
\hline \multirow{3}{*}{ Socio demographic data } & \multicolumn{4}{|c|}{ Groups } & \multirow{3}{*}{$\chi^{2}$} & \multirow{3}{*}{ P-value } \\
\hline & \multicolumn{2}{|c|}{ Study $(n=40)$} & \multicolumn{2}{|c|}{ Control $(n=40)$} & & \\
\hline & No. & $\%$ & No. & $\%$ & & \\
\hline \multicolumn{7}{|l|}{ Age / years } \\
\hline $60-63$ & 22 & 55 & 23 & 57.5 & \multirow[t]{3}{*}{.817} & \multirow{3}{*}{$\begin{array}{l}.930 \\
\mathrm{NS}\end{array}$} \\
\hline 64- 67 & 18 & 45 & 17 & 42.5 & & \\
\hline Mean \pm SD & \multicolumn{2}{|c|}{$63.9 \pm 2.1$ years } & \multicolumn{2}{|c|}{$62.8 \pm 2.0$ years } & & \\
\hline \multicolumn{7}{|l|}{ Gender } \\
\hline Male & 18 & 45 & 26 & 65 & \multirow[t]{2}{*}{.201} & \multirow[t]{2}{*}{$.654 \mathrm{NS}$} \\
\hline Female & 22 & 55 & 14 & 35 & & \\
\hline \multicolumn{7}{|l|}{ Educational level } \\
\hline Illiterate & 19 & 47.5 & 17 & 42.5 & \multirow{3}{*}{.244} & \multirow{3}{*}{$\begin{array}{l}.885 \\
\text { NS }\end{array}$} \\
\hline Read and write & 14 & 35 & 16 & 40 & & \\
\hline Basic & 7 & 17.5 & 7 & 17.5 & & \\
\hline \multicolumn{5}{|l|}{ Occupational status } & \multirow{4}{*}{1.145} & \multirow{4}{*}{$\begin{array}{l}.925 \\
\mathrm{NS}\end{array}$} \\
\hline Worker & 8 & 20 & 12 & 30 & & \\
\hline Retired & 10 & 25 & $1 \leq$ & ro & & \\
\hline House wife & 22 & 55 & $1 \varepsilon$ & ro & & \\
\hline
\end{tabular}

$\mathrm{NS}=$ not significant

Table (1): Showed that, the mean age among study and control groups was nearly similar $(63.9 \pm 2.1$ years, and $62.8 \pm 2.0$ years) respectively. In respect to gender; The results revealed that $55 \%$ of the study group were female while $65 \%$ of the control group were male. Concerning to educational level; the study data demonstrated that, $47.5 \%$ of the study group were illiterate. While, $17.5 \%$ of them were basic education. Lastly; the findings displayed that, $55 \%, 35 \%$ respectively among the study and control groups were house wives. There were no statistical significant differences between both groups in relation to socio demographic characteristic. 

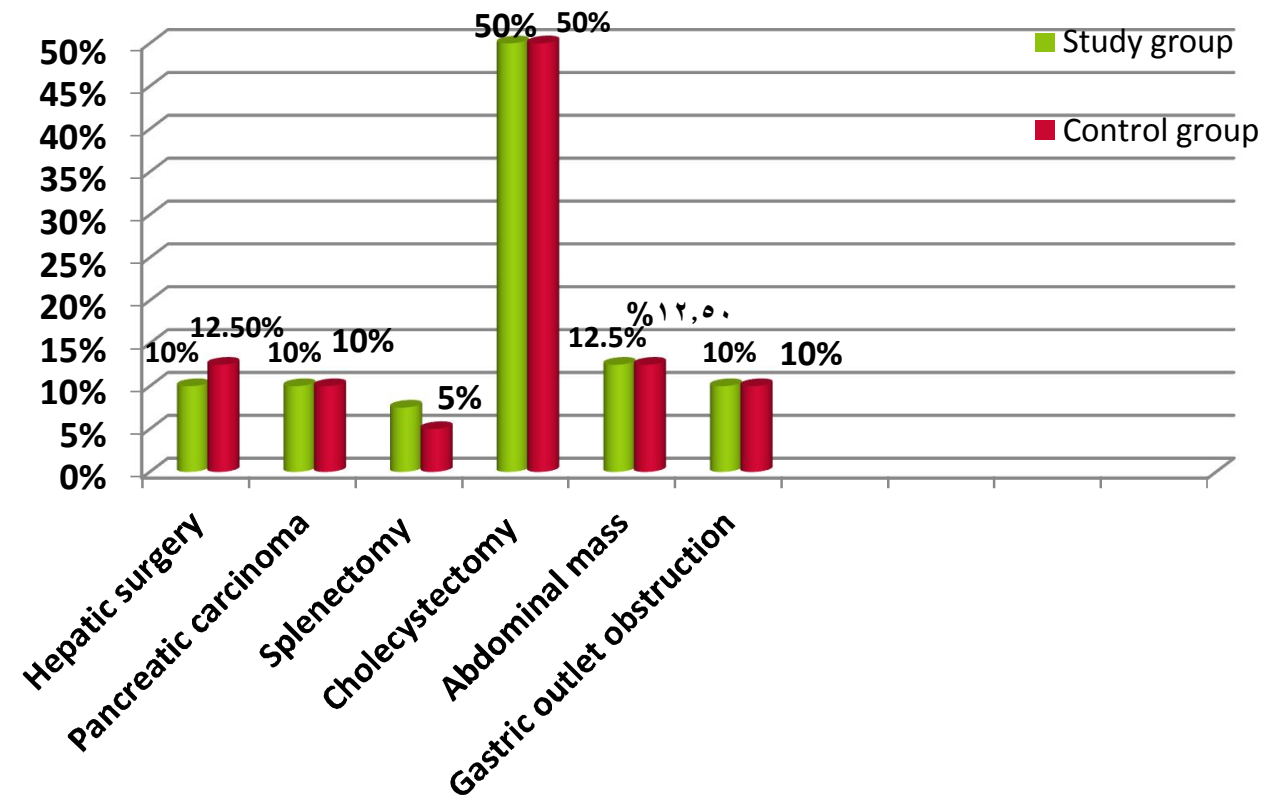

Figure (1): Distribution of the type of surgery among the study and control groups $(n=80)$.

Figure (1): illustrated that, $50 \%$ of both groups were performed cholecystectomy.

Table (2):- Comparison between the study and control groups regarding to auscultatory breathing sound in the 1st five days postoperative $(n=80)$.

\begin{tabular}{|c|c|c|c|c|c|c|}
\hline \multicolumn{5}{|l|}{ Groups } & \multirow{3}{*}{$\mathrm{X} 2$} & \multirow{3}{*}{ P-value } \\
\hline \multirow{2}{*}{$\begin{array}{l}\text { Auscultatory } \frac{r}{r e a d i n g} \\
\text { from 1st to } 5 \text { th day }\end{array}$} & \multicolumn{2}{|c|}{ Study } & \multicolumn{2}{|c|}{ Control } & & \\
\hline & No. & $\%$ & No. & $\%$ & & \\
\hline \multicolumn{7}{|l|}{ Breathing sound } \\
\hline \multicolumn{7}{|l|}{ 1st day } \\
\hline Clear & 40 & 100 & 40 & 100 & Fisher exact & ......... \\
\hline \multicolumn{7}{|l|}{ 2nd day } \\
\hline Clear & 40 & 100 & 40 & 100 & Fisher exact & $\ldots \ldots$ \\
\hline \multicolumn{7}{|l|}{ 3rd day } \\
\hline Clear & 37 & 92.5 & 10 & 25.0 & \multirow[t]{2}{*}{37.602} & \multirow[t]{2}{*}{$.000 * *$} \\
\hline Crackles & 3 & 7.5 & 30 & 75.0 & & \\
\hline \multicolumn{7}{|l|}{ 4th day } \\
\hline Clear & 35 & 87.5 & 6 & 15 & \multirow[t]{2}{*}{31.745} & \multirow[t]{2}{*}{$.000 * *$} \\
\hline Crackles & 5 & 12.5 & 34 & 85 & & \\
\hline \multicolumn{7}{|l|}{5 th day } \\
\hline Clear & 35 & 87.5 & 6 & 15 & \multirow[t]{2}{*}{32.125} & \multirow{2}{*}{$.000 * *$} \\
\hline Crackles & 5 & 12.5 & 34 & 85 & & \\
\hline
\end{tabular}

** highly statistical significance differences

Table (2):- Represented that, $100 \%, 100 \%, 92.5 \%$, $87.5 \%, 87.5 \%$ respectively of the study group had clear chest sound along the 1st five days postoperatively, in comparing with, $100 \%$ of control group had clear chest sound only at the 1 st and 2 nd days postoperatively and in the rest of days was had crackles. There were high statistical significant differences between the both groups regarding to breathing sound in which $\mathrm{p}$-value $=.000^{* *}$ 
Table(3):- Comparison between the study and control groups regarding to RTIs manifestations through the 1st five days postoperative $(\mathbf{n}=\mathbf{8 0})$.

\begin{tabular}{|c|c|c|c|c|c|c|}
\hline \multicolumn{7}{|l|}{ Groups } \\
\hline \multirow[t]{2}{*}{ RTIs manifestations } & \multicolumn{2}{|c|}{ Study $(n=40)$} & \multicolumn{2}{|c|}{ Control } & \multirow{2}{*}{$\mathrm{X} 2$} & \multirow[t]{2}{*}{ P-value } \\
\hline & No. & $\%$ & No. & $\%$ & & \\
\hline \multicolumn{7}{|c|}{ Abnormal respiratory manifestations } \\
\hline Yes & 5 & 12.5 & 34 & 85.0 & \multirow[t]{2}{*}{42.076} & \multirow{2}{*}{$.000 * *$} \\
\hline No & 35 & 87.5 & 6 & 15.0 & & \\
\hline \multicolumn{7}{|c|}{ Neuromuscular and sleeping manifestations } \\
\hline Yes & 2 & 5 & 24 & 60 & \multirow[t]{2}{*}{29.463} & \multirow[t]{2}{*}{$.000 * *$} \\
\hline No & 38 & 95 & 16 & 40 & & \\
\hline \multicolumn{7}{|l|}{ Chest $\mathrm{x}$-ray findings } \\
\hline Positive & 5 & 12.5 & 34 & 85.0 & \multirow[t]{2}{*}{42.076} & \multirow[t]{2}{*}{$.000 * *$} \\
\hline Negative & 35 & 87.5 & 6 & 15.0 & & \\
\hline
\end{tabular}

Table (3):- Showed that, $12.5 \%$ of the study group had abnormal respiratory manifestations \& positive chest Xray findings, in contrast to, $85.0 \%$ of the control group had abnormal respiratory manifestations \& positive chest X-ray findings with other manifestations constituted $60 \%, 62.5 \%$,
\& $62.5 \%$ respectively. There were high statistical significant differences among both groups regarding the manifestations of RTIs, in which P-value $=.000^{* *}, .027^{*}$, $.021 *$

Table (13):- Correlation between the socio-demographic data and RTIs manifestations at the 1st five days postoperative $(\mathbf{n}=\mathbf{8 0})$.

\begin{tabular}{|l|l|l|l|l|}
\hline \multirow{2}{*}{ Socio-demographic data } & \multicolumn{3}{l|}{ RTIs manifestations } \\
\cline { 2 - 5 } & \multicolumn{2}{|l|}{ Study group } & \multicolumn{2}{l|}{ Control group } \\
\cline { 2 - 5 } & $\mathrm{r}$ & $\mathrm{P}-$ value & $\mathrm{r}$ & $\mathrm{P}$ - value \\
\hline Age & $.903-$ & $.020^{*}$ & .789 & $.008^{* *}$ \\
\hline Gender & $.222-$ & .198 & .779 & $.023 *$ \\
\hline Occupation & .129 & .244 & .450 & .123 \\
\hline Educational level & .627 & .179 & .162 & .298 \\
\hline
\end{tabular}

* statistically significance differences

RTIs $=$ Respiratory tract infections.

Table (13):- Founded that, there was a strong negative correlation (.903-, .222-) between the study group' average age \& gender and RTIs manifestations with statistical significant differences $(\mathrm{P}-$ value $=.020 *, .198 *)$ respectively. While, there was a strong positive correlation $(.789, .779)$ between the control group' average age \& gender and RTIs manifestations with statistical significant differences $\left(\mathrm{P}-\right.$ value $=\left(.008^{* *}, .023 *\right)$. As well, results revealed that, there was weak positive correlation $(.129$, $.627, .275, .450, .162, .148)$ respectively among both groups between the rest of their socio-demographic data and RTIs manifestations.

Table (4):- Correlation between frequency of early ambulation steps and peripheral oxygen saturation measurements at the 1 st five days postoperative $(n=80)$.

\begin{tabular}{|l|l|l|l|l|}
\hline \multirow{2}{*}{$\begin{array}{l}\text { Frequency of early } \\
\text { ambulation steps }\end{array}$} & \multicolumn{4}{l}{ Peripheral oxygen saturation measurements (SPO2) } \\
\cline { 2 - 5 } & \multicolumn{2}{|l|}{ Study group } & \multicolumn{2}{l|}{ Control group } \\
\cline { 2 - 5 } & $\mathrm{r}$ & $\mathrm{P}-$ value & $\mathrm{r}$ & $\mathrm{P}$ - value \\
\hline Ankle planter flexion & .965 & $.000^{* *}$ & .980 & $.050^{*}$ \\
\hline Site in bed & .842 & $.004^{* *}$ & .695 & $.038^{*}$ \\
\hline Standing & .977 & $.000^{* *}$ & .885 & $.014^{*}$ \\
\hline Walking in room & .983 & $.015^{*}$ & .732 & $.042^{*}$ \\
\hline Walking in corridor & .972 & $.000^{* *}$ & .710 & $.052^{*}$ \\
\hline
\end{tabular}




\begin{tabular}{|c|c|c|c|c|}
\hline \multirow{3}{*}{$\begin{array}{l}\text { Frequency of early } \\
\text { ambulation steps }\end{array}$} & \multicolumn{4}{|c|}{ Peripheral oxygen saturation measurements (SPO2) } \\
\hline & \multicolumn{2}{|c|}{ Study group } & \multicolumn{2}{|c|}{ Control group } \\
\hline & $\mathrm{r}$ & $\mathrm{P}$ - value & $\mathrm{r}$ & $\mathrm{P}$ - value \\
\hline Stair climbing & .962 & $.005^{* *}$ & .842 & $.036^{*}$ \\
\hline Side lying\& positions & .704 & $.013^{*}$ & .801 & $.026^{*}$ \\
\hline
\end{tabular}

Table(4):- displayed that, there was a statistical significant positive correlation among both groups between all items of frequency of early ambulation steps and normal peripheral oxygen saturation measurements.

Table (5):- Correlation between RTIs manifestations and frequency of early ambulation steps along the 1st five days postoperative $(n=80)$.

\begin{tabular}{|c|c|c|c|c|}
\hline \multirow{3}{*}{ RTIs manifestations } & \multicolumn{4}{|c|}{ Frequency of early ambulation steps } \\
\hline & \multicolumn{2}{|c|}{ Study group } & \multicolumn{2}{|c|}{ Control group } \\
\hline & $\mathrm{r}$ & $P$ - value & $\mathrm{r}$ & $\mathrm{P}$ - value \\
\hline Respiratory manifestations & $.008-$ & $.000 * *$ & .916 & $.005 *$ \\
\hline Neuromuscular manifestations & $.902-$ & $.000 * *$ & .789 & $.035 *$ \\
\hline GIT manifestations & $.951-$ & $.000 * *$ & .639 & $.056 *$ \\
\hline Eye and ear manifestations & $.855-$ & $.000^{* *}$ & .695 & $.057 *$ \\
\hline Chest $\mathrm{X}$ - ray findings & $.689-$ & $.001 * *$ & .981 & $.004 * *$ \\
\hline
\end{tabular}

* statistically significance differences RTIs $=$ Respiratory tract infection
** highly statistical significance differences
Table (5):- Showed that, there was a strong negative correlation among the study group between absence of all RTIs manifestations items and high

\section{Discussion:}

The present study findings showed that, half of both groups were had cholecystitis. In my opinion, this may be rationalized by incidence of cholecystitis and gallstones increases with age and among female due to decreased gallbladder motility and cholesterol metabolism in older people. These results corresponded by Bhandari, (2017), who reported that, cholecystitis and gallstones increase with old age by 13

The current study data represented that, the vast majority of the study group had clear chest sound, while the vast majority of the control group had crackles. I thought that this may be due to applying chest physiotherapy along with incentive spirometry results in improved clearance of bronchial secretion from lung periphery to more proximal branch thus aids expectoration which enhancing pulmonary hygiene and preventing accumulation of secretions.

Similarly, AbdElgaphar, \& Soliman, (2015), who analyzed the effect of early post-anesthetic chest physiotherapy on elderly patients undergoing upper abdominal surgery. The investigator summarized that, $(73.3,100 \%)$ respectively of the study group had clear chest sound at the second and third assessment, compared with $(56.8 \% 83.1 \%)$ respectively of the control group had crepitation and crackles. While, these results were contradicted with, Kale, (2017), who investigated the effectiveness of pre-operative deep breathing exercise on frequency of early ambulation steps performance with highly statistical significance differences, while, reverse results with the control group.

post-operative patients of abdominal surgery; he revealed that, $100 \%$ of the experimental group had clear lung sounds by the 7 th postoperative day, whereas in the control group, $76.66 \%$ had clear lung sounds at the same days.

The current study findings showed that, the minority of the study group were had abnormal respiratory manifestations in contrast to, the majority of the control group had abnormal respiratory manifestations with other manifestations, the possible explanation for this was; the supervision and close monitoring of patients in the study group to ensure proper performance and adherence to the nursing care strategies significantly minimize the occurrence of postoperative RTIs.

The present study findings supported by Abdelaal., (2017), who evaluated the effectiveness of preoperative physical and respiratory therapy on postoperative pulmonary functions and complications after laparoscopic upper abdominal surgery. He established that, by the 5th postoperative day after completion of intervention, only 7 patients $(27 \%)$ in the treatment group had postoperative pulmonary infections, compared with 15/24 (62.5\%) patients in the control group had postoperative pulmonary infections and $\mathrm{P}=.034$. Moreover, Boden, ( 2018) who discussed that, preoperative education and breathing exercise training alone is reported to be associated with a $75 \%$ relative risk reduction and absolute risk reduction of $20 \%$ in postoperative RTIs. 
The present study results founded that, there was a strong negative correlation between the study group' average age and all RTIs manifestations. While, there was a strong positive correlation between the control group' average age and all RTIs manifestations. This may be regarded to the effectiveness of incentive spirometery and chest physiotherapy in improving ventilation \& oxygenation, as well, their greater benefits in airway clearance and reducing postoperative RTIs despite old age.

These present study findings agreed with, Tadyanemhandu, (2017) \& Inokuchi et al., (2014), who stated that, age $\geq 60$ years was not associated with the occurrence of postoperative RTIs. By contrast, the current study results was contradicted with, Miskovic \& Lumb, (2017), who stated that, the more the age increased, the more the risk for postoperative RTIs, and he revealed that, from 60- to 69-yr-olds, odds ratios (OR) for RTIs were 2.1 (1.7-2.6) and from 70- to 79-yr-olds, OR were 3.1 (2.1-4.4), and above $80 \mathrm{yr}$ of age, the risk increased further to an OR of $5.1(1.9-13.3)$.

The present study findings, revealed that, male gender among the control group represented strong positive correlation with RTIs manifestations. which may be due to more than half percent of the control group were cigarette smoking which may increase the susceptibility to RTIs. These results were in corroborated with Shah, et al., (2017), and Kodra, et al., (2016), who demonstrated that, male elderly patients with open abdominal surgery had more postoperative pulmonary infections $(24.24 \%)$ than female elderly $(8.33 \%)$. They suggested that; this due to men tend to breathe more with their diaphragm and women breathe more with their thorax; thus when the movements of the diaphragm are restricted after the abdominal operations, the males suffer more from lack of expansion of the lungs.

On the other hand, the findings of the present study were contradicted with, de Almeida, et al., (2017), who discussed that, female patients were more prone than male patients to present postoperative RTIs as women generally have reduced airway diameter, lower resting lung diffusing capacity, smaller lung volumes, and lower maximal expiratory flow rates than men, even when corrected for age and standing height. Consequently, women are more likely to experience greater mechanical limits to expiratory flow compared with men, creating a smaller maximal flow. Furthermore, Ávila \& Fenili, (2017), and Tadyanemhandu et al., (2017), disagreed with the current study findings in which they documented that, gender was not associated with postoperative RTIs.

The study results showed that, there was a statistical significant positive correlation among both study groups between all items of frequency of early ambulation steps and normal peripheral oxygen saturation measurements. In my opinion, this may be explained by less or more ambulation performance correlated positively with normal range of $\mathrm{SpO} 2$.

Findings of the current study were in congruent with, Patman, (2017), investigated the early ambulation during immediate postoperative period among elderly patients undergoing upper abdominal surgery, and he founded that, there was significant increase in the oxygen saturation ( from $94.7 \pm 2.4 \%$ to $96.0 \pm 2.6 \%$ ) in the intervention group after performing early ambulation.

P a g e | 117
Findings of the present study showed that, there was a strong positive correlation among the study group between high frequency of early ambulation steps performing and absence of RTIs manifestations, while, reverse results with the control group, due to early ambulation and frequent position changing improves the forced vital capacity, maximum voluntary ventilation and arterial oxygenation .

These results were in congruent with, Silva et al., (2013), and Haines et al., (2013), who established that, implementing postoperative early mobilization was a key concept in surgical recovery and overall improvement of medical conditions and it alone could provide a reduction by $81 \%$ in RTIs rates. Delayed ambulation has also been associated with three times more likely to have postoperative RTIs diagnosis for each day they did not mobilize away from the bedside Also, these results supported by Boden, et al., (2018), who found that, incidence of postoperative pulmonary infection reduced by $50 \%$ with early ambulation.

\section{Conclusion}

Based on current study findings, early ambulation had been demonstrated to have a synergetic positive effect on reducing postoperative RTIs, improving respiratory parameters, oxygenation, and lung ventilation.

\section{Recommendations:}

- Creating respiratory assessment sheet for every patient with or without RTIs during hospitalization is important in preventing and reducing severity of postoperative RTIs.

- Regular training and educational programs about the early ambulation (especially for elderly) should be developed to the health team members especially the nursing staff because they are the ones implementing them

- Encourage further researches regarding the role of hospital setting and patients-related factors on respiratory tract infection postoperatively.

\section{Acknowledgment}

The researchers would like to acknowledge the contribution of all participants who kindly agreed to take part in the study. They generously gave their time and attention to conduct this study. This study would have been impossible without their generosity.

\section{References}

[1]. Tariq, M. I., Khan, A. A., Khalid, Z., Farheen, H., Siddiqi, F. A., \& Amjad, I. (2017). Effect of Early $\leq$ 3 Mets (Metabolic Equivalent of Tasks) of Physical Activity on Patient's Outcome after Cardiac Surgery. Journal of the College of Physicians and Surgeons--Pakistan: JCPSP, 27(8), 490-494.

[2]. Chen, C. C.-H., Lin, M.-T., Tien, Y.-W ‘.Yen, C.J., Huang, G.-H., \& Inouye, S. K. (2011). Modified Aml S., et al 
hospital elder life program: effects on abdominal surgery patients. Journal of the American College of Surgeons, 213(2), 245-252.

[3]. Chavan, D. R., Kannur, S., Metan, B., \&Kullolli, G. (2017). A prospective study on geriatric abdominal surgical emergencies. International Journal of Research in Medical Sciences, 2(3), 963971.

[4]. Ávila, A \& Fenili. Incidence and risk factors for postoperative pulmonary complications in patients undergoing thoracic and abdominal surgeries. Rev. Col. Bras. Cir. 2017; 44(3): 284-292.

[5]. Qureshi I, Jitendra Gothwal, r Sani Pasrija, Ajay Joshi Dr Sanjay Patidar, Jitendra Gothwal. (2018). Study on Geriatric Abdominal Surgical Procedures in Tertiary Care Hospital. https://dx.doi.org/10.18535/jmscr/v6i2.207JMSCR Volume 06 Issue 02 February .

[6]. Boden, I., Skinner, E. H., Browning, L., Reeve, J., Anderson, L., Hill, C., . . . Denehy, L. (2018). Preoperative physiotherapy for the prevention of respiratory complications after upper abdominal surgery: pragmatic, double blinded, multicentre randomised controlled trial. bmj, 360, j5916.

[7]. Masse, S., Capai, L., \& Falchi, A. (2017). Epidemiology of Respiratory Pathogens among Elderly Nursing Home Residents with Acute Respiratory Infections in Corsica, France, 20132017. BioMed Research International, 2017.

[8]. Tadyanemhandu, C., Mukombachoto, R., Nhunzvi, C., Kaseke, F., Chikwasha, V., Chengetanai, S ‘. \&Manie, S. (2017). The prevalence of pulmonary complications after thoracic and abdominal surgery and associated risk factors in patients admitted at a government hospital in Harare, Zimbabwe-a retrospective study. Perioperative Medicine, 6(1), 11.

[9]. Haines KJ, Skinner EH, "Berney S. Association of postoperative pulmonary complications with delayed mobilization following major abdominal surgery, an observational cohort study. Physiotherapy.

[10]. Patman, S., Bartley, A., Ferraz, A., \& Bunting, C. (2017). Physiotherapy in upper abdominal surgerywhat is current practice in Australia? Archives o physiotherapy, 7(1), 11

[11]. Kumar, A. S., Alaparthi, G. K., Augustine, A. J., Pazhyaottayil, Z. C., Ramakrishna, A., \& Krishnakumar, S. K. (2016). Comparison of flow and volume incentive spirometry on pulmonary function and exercise tolerance in open abdominal surgery: a randomized clinical trial. Journal of clinical and diagnostic research: JCDR, 10(1), KC01
[12]. Do Nascimento Junior, P., Modolo, N. S., Andrade, S., Guimaraes ‘M. M., Braz, L. G., \& El Dib, R. (2014). Incentive spirometry for prevention of postoperative pulmonary complications in upper abdominal surgery. The Cochrane Library .

[13]. Özkan, E., Fersahoğlu, M. M., Dulundu, E., Özel, Y., Yıldız, M. K., \& Topaloğlu, Ü. (2010). Factors affecting mortality and morbidity in emergency abdominalsurgery in geriatric patients. Turkish Journal of Trauma and Emergency Surgery, 16(5), 439-444.

[14]. Kale, P. M., Mohite, V. R., Chendake, M. B., \& Gholap, M. C. (2017). The Effectiveness of pre-operative deep breathing exercise on post-operative patients of abdominal surgery.Asian J Pharm Clin Res, 10(2), 157-160 .

[15]. Parry S, Denehy L, Berney S, Browning L (2014) Clinical application of the Melbourne risk prediction tool in a high-risk upper abdominal surgical population: an observational cohort study. Physiotherapy 100(1): 47-53. doi:10.1016/j.physio. 05.002.

[16]. Silva Y, Li S, Rickard M (2013) Does the addition of deep breathing exercises to physiotherapy-directed early mobilisation alter patient outcomes following high-risk open upper abdominal surgery? Physiotherapy 99(3): 187-193. doi:10.1016/j.physio.2012.09.006

[17]. Racz, J., Dubois, L., Katchky, A., \& Wall, W. (2012). Elective and emergency abdominal surgery in patients 90 years of age or older. Canadian Journal of Surgery, 55(5), 322-328. http://doi.org/10.1503/cjs.007611

[18]. Torrance, A. D. W., Powell, S. L., \& Griffiths, E. A. (2015). Emergency surgery in the elderly: challenges and solutions. Open Access Emergency Medicine $\square$ : OAEM, 7, 55-68. http://doi.org/10.2147/OAEM.S68324

[19]. Bhandari, T. R., et al. (2017). "Laparoscopic cholecystectomy in the elderly: An experience at a tertiary care hospital in western nepal." Surgery research and practice 2017.

[20]. Castelino, T. (2016). Impact of Early Mobilization on Outcomes After Colorectal Surgery, McGill University Libraries.

[21]. De Almeida, E., et al. (2017). "Early mobilization programme improves functional capacity after major abdominal cancer surgery: a randomized controlled trial." BJA: British Journal of Anaesthesia 119(5): 900-907..

[22]. Jing, R., et al. (2018). "Incidence and risk factors of postoperative pulmonary complications." International Journal Of Clinical And Experimental Medicine 11(1): 285-294. 
[23]. Miskovic, A. and A. Lumb (2017). "Postoperative pulmonary complications." BJA: British Journal of Anaesthesia 118(3): 317-334.

[24]. Organizations, J. C. o. A. o. H. University of Wisconsin Hospitals and Clinics Authority Quality Report.

[25]. Sabaté, S., et al. (2014). "Predicting postoperative pulmonary complications: implications for outcomes and costs." Current Opinion in Anesthesiology 27(2): 201-209.

[26]. Tan, P. X.-Z and G.-C. Chua (2013). Nursing care of the elderly surgical patients. Colorectal Cancer in the Elderly, Springer: 121-140.

[27]. Watt, J., et al. (2018). "Identifying older adults at risk of harm following elective surgery: a systematic review and meta-analysis." BMC medicine 16(1): 2.

[28]. Griffiths, R., Beech, F., Brown, A., Dhesi, J., Foo, I., Goodall, J., ... \& White, S. (2014). Perioperative care of the elderly: Association of Anaesthetists of Great Britain and Ireland. Anaesthesia, 69, 81-98.

[29]. AbdElgaphar, S., \& Soliman, G. (2015). The Effect of Early Post-anesthetic Chest Physiotherapy Nursing Intervention on Patients Undergoing Upper Abdominal Surgery. IOSR Journal of Nursing And Health Science, 4(4), 1-7.

[30]. Ukkonen, M. (2017). Outcome of Emergency Gastrointestinal Procedures inthe Elderly . ACADEMIC DISSERTATION Acta Universitatis Tamperensis 2250. Tampere University Press. Tampere.1-98.

[31]. Chatterley, L. (2017). Improving Nurse Knowledge and Attitudes of Early Mobilization of the Postoperative Patient .Master theses, Dissertation. Graduate research and major paper overview. 188. https://digitalcommons.ric.edu/et.

[32]. Singh, K., Sudheer, D., Dwivedi, S. K., \& Goyal, M. (2017). Efficacy of Chest Physiotherapy and Incentive Spirometry on Pulmonary Function in Post operative Period after Abdominal Surgery; A Comparative Study. International Journal of
Innovative Research in Medical Science, 2(08), 1240-to1243.

[33]. Castelino, T. (2016). Impact of Early Mobilization on Outcomes After Colorectal Surgery. Master of Science. McGill University, Montreal.1-102.

[34]. Churchill surgical physiotherapy team, (2018). Physiptherapy advise after abdominal surgery. Oxford University, Hospital NHS Trust. Joint Commission on Accreditation of Healthcare Organizations. University of Wisconsin Hospitals and Clinics Authority Quality Report. https://www.ouh.nhs.uk/patientguide/leaflets/files/11733Pabdominal.pdf.

[35]. Shah, U., Contractor, N., \& Mehta, K. (2017). Preoperative Pulmonary Function Tests in COPD Patients Posted For Major Upper Abdominal Surgeries: Evaluation of Postoperative Pulmonary Complications. National Journal of Integrated Research in Medicine, 8(3).

[36]. Inokuchi, M., Kato, K., Sugita, H., Otsuki, S., \& Kojima, K. (2014). Impact of comorbidities on postoperative complications in patients undergoing laparoscopy-assisted gastrectomy for gastric cancer. BMC surgery, 14(1), 97.

[37]. Tadyanemhandu, C., Mukombachoto, R., Nhunzvi, C., Kaseke, F., Chikwasha, V., Chengetanai, S\& ‘.Manie, S. (2017). The prevalence of pulmonary complications after thoracic and abdominal surgery and associated risk factors in patients admitted at a government hospital in Harare, Zimbabwe-a retrospective study. Perioperative Medicine, 6(1), 11.

[38]. Kodra, N., Shpata, V., \& Ohri, I. (2016). Risk factors for postoperative pulmonary complications after abdominal surgery. Open access Macedonian journal of medical sciences, 4(2), 259.

[39]. Moore, J. A., Conway, D. H., Thomas, N., Cummings, D., \& Atkinson, D. (2017). Impact of a peri $\square$ operative quality improvement programme on postoperative pulmonary complications. Anaesthesia, 72(3), 317-327 